\title{
IKON-IKON SEJARAH \& PERATURAN BULU TANGKIS UNTUK INFOGRAFIS
}

\author{
Muhammad Yahya Wahyudin ${ }^{1)}$, Puji Anto ${ }^{2)}$ \\ Program Studi Desain Komunikasi Visual, \\ Fakultas Bahasa dan Seni, Universitas Indraprasta PGRI \\ Jl. Nangka No. 58 C, Tanjung Barat, Jakarta 12530, Indonesia \\ muhammadyahyawahyudin@gmail.com
}

\begin{abstract}
Abstrak
Tujuan Penelitian ini adalah merancang ikon-ikon sejarah \& peraturan bulu tangkis untuk infografis. Metode penelitian yang digunakan adalah jenis penelitian kualitatif. Penggunaan metode kualitatif dalam melakukan penelitian ini sangat efektif karena data-data yang dihasilkan merupakan hasil pencarian dan pengumpulan studi pustaka berupa buku-buku, skripsi, jurnal ilmiah, dan dokumen online, serta observasi. Hasil rancangan yang dibuat menggunakan gaya visual flat design dan pengguanaan warna, seperti warna merah, yang melambangkan semangat yang berkobar, simbol keberanian, dan rasa bahagia sehingga dapat menggambarkan sosok para pejuang atlet legendaris kita dalam memperebutkan kejuaraan dunia. Selain itu, terdapat warna biru yang memiliki kesan atau makna sejuk, nyaman, dan tenang, yang dimaksudkan agar audience bisa nyaman ketika melihat media infografis tersebut.
\end{abstract}

Kata Kunci: Ikon, Infografis, Bulu Tangkis Indonesia, Sejarah

\begin{abstract}
The aim of this study was to historical icons \& badminton rules of infographics. The research method used is a type of qualitative research. The use of qualitative methods in conducting this research is very effective because the data produced are the results of searches and collection of library studies in the form of books, theses, scientific journals, and online documents, as well as observations. The design results are made using a visual flat design style and the use of colors including red, which symbolizes a burning spirit, a symbol of courage, and a sense of happiness. So that it can describe the figure of our legendary athlete fighters in fighting for the world championship. In addition, there is a blue color that has a cool, comfortable and calm impression or meaning, which is intended to make the audience comfortable when viewing the media infographics.
\end{abstract}

Keywords: Icon, Infographic, Indonesian Badminton, History

\section{PENDAHULUAN}

Bulu tangkis merupakan olahraga yang familear di kalangan masyarakat, termasuk di dalamnya adalah prestasi-prestasi yang mendunia sehingga membuat banyak masyarakat terutama anakanak ikut bermain bulu tangkis walaupun tidak bermain langsung di lapangan dan tidak mengikuti aturan-aturan yang sudah ditetapkan. Bulu tangkis sendiri dapat menjadi sarana penghubung yang positif di kalangan masyarakat.

Bulu tangkis adalah permainan yang dimainkan oleh satu orang melawan satu orang (single) atau dua orang melawan dua orang (double) dengan cara memukul kok (shuttle cock) 
menggunakan raket agar melewati net, sehingga berusaha mengembalikan kok tersebut agar tidak jatuh di area sendiri. Bulu tangkis dapat dimainkan secara ganda maupun tunggal, dilakukan oleh pria maupun wanita, dan ganda campuran.

Dalam merancang infografis perlunya ikon-ikon, khususnya bulu tangkis adalah memberikan suatu pesan adanya referensi yang akurat dari gambar atau ikon yang dibuat. Secara umum ikon dibuat untuk memberikan pesan lebih cepat, dan menarik agar audiens bisa lebih mudah membacanya karena ikon itu adalah salah satu pengganti dari makna tulisan, contohnya seperti ikon kamar mandi yang diubah menggunakan gambar pria dan wanita untuk mempersingkat waktu apabila dalam ke adaan darurat. .

\section{METODE PENELITIAN}

Dalam merancang ikon, baik itu sejarah, maupun regulasi dalam permainan bulu tangkis untuk infografis menggunakan metode penelitian kualitatif. Metode ini dipilih karena dilakukan dengan cara observasi atau pengamatan secara interaktif dan kajian pustaka. Penelitian kualitatif merupakan usaha menggambarkan kehidupan masyarakat, tingkah laku, sejarah, fungsionalisme organisasi, pergerakan social, dan hubungan antarsesama yang bersifat kekerabatn (Ghony dan Almanshur, 2014: 25). Selain itu, dengan penelitian kualitatif pengumpulan data tidak dibatasi pada kategori-kategori tertentu sehingga penelitian mengenai ikon prestasi bulu tangkis untuk infografis dapat dilakukan lebih mendalam dan mendetail.

\section{HASIL DAN PEMBAHASAN \\ Objek Penelitian}

Awal mulanya bulu tangkis dimainkan di Inggris. Pada waktu itu alat yang digunakan adalah dayung/tongkat (Battledore) dan memastikan kok tidak jatuh atau menyentuh tanah. Permainan ini cukup populer dikalangan warga London, karena permainan ini dimainkan di setiap sudut jalan. Pada tahun 1854 di London sebuah majalah memublikasikan kartun tentang permainan ini. Pada saat zaman kolonial Inggris, permainan ini dibawa ke Jepang, Cina, dan Siam (Thailand) oleh para tantara. Kemudian, permainan ini menjadi permainan yang dilakukan di negara kolonial Inggris.

Berasal dari permainan tersebut maka dikembangkan menjadi olahraga yang lebih kompetitif sebagai hiburan. Permainan yang kompetitif pertama kali dimainkan di India, Pune, pada abad ke-19 yang dikembangkan oleh tentara Britania. Permainan ini ditambahkan alat menggunakan jaring/net sebagai pembatas lapangan yang di tempatkan di tengah. Karena dimainkan di Pune inilah, permainan bulu tangkis lebih dikenal sebagai Poona pada masa itu dan akhirnya dibawa kembali ke Inggris (1850-an). Olahraga ini, pada tahun 1860 dalam sebuah paraflet oleh Isaac Spratt, seorang penyalur mainan Inggris, berjudul "Badminton Battledore-a new game" (Battledore bulu tangkis sebuah permainan baru) mendapatkan nama badminton/bulu tangkis. Hal ini menggambarkan di Gedung Badminton (Badminton House) estat Duke of Beaufort's di Gloucestershire, Inggris sebagai tempat untuk memainkan bulu tangkis. Permainan badminton pada zaman itu belum jelas tentang peraturan yang digunakan dan tahun 1877 rancangan peraturan pertama kalinya dibuat oleh klub Badminton Bath di Inggris. Kemudian, pada tahun 1893-1951 para tokoh Indonesia menyelenggarakan kongres di Bandung dan menghasilkan keputusan serta melahirkan badan bulu tangkis tingkat nasional, yaitu PBSI (Persatuan Bulu Tangkis Seluruh Indonesia) tertanggal 5 Mei 1951.

Pertemuan tanggal 5 Mei 1951 di kota Bandung merupakan awal mula sejarah perbulutangkisan Indonesia. Melahirkan PBSI (Persatuan Bulu Tangkis Seluruh Indonesia) dan merupakan kongres pertama PBSI. Ketua umumnya adalah A. Rochdi Partaatmadja, Ketua I: Soedirman, Ketua II: Tri Tjondrokoesoemo, Sekertaris I: Amir, Sekertaris II: E. Soemantri, Bendahara I: Rachim, Bendahara II: Liem Soei Liong. Kepegurusan tersebut mengubah skema kepengurusan dibawahnya, kepengurasan tingkat provinsi menjadi pengda (pengurus daerah), sedangkan kotamadya menjadi Pengcab (Pengurus Cabang). Hingga akhir bulan Agustus 1977 ada 25 Pengda di seluruh Indonesia (kecuali Provinsi Timor-Timor) dan sebanyak 224 Pengcab, sedangkan jumlah perkumpulan yang menjadi anggota PBSI diperkirakan 2000 perkumpulan. 
Setelah memiliki badan induk olahraga sendiri bulu tangkis mendaftar menjadi anggota resmi BWF pada tahun 1953 (Yuliawan, 2017: 1).

Pada tahun 1934 didirikan International Badminton Federation (IBF) beranggotakan Inggris, Irlandia, Skotlandia, Wales, Denmark, Belanda, Kanada, Selandia Baru, dan Prancis sebagai anggota-anggota pelopornya. Di Madrid, Spanyol, IBF Extraordinary General Meeting, pada September 2006, diterimanya usulan mengubah nama International Badminton Federation menjadi Badminton World Federation (BWF) oleh seluruh 206 delegasi dengan suara bulat.

Fungsi dari Badminton World Federation atau disingkat dengan BWF, yaitu untuk mengatur, mempromosikan, mengelola, dan mengembangkan olahraga bulu tangkis dunia. BWF beranggotakan 180 negara berkantor pusat di Kuala Lumpur, Malaysia. Kualifikasi Kejuaraan Dunia dan Olimpiade perlu diatur, maka BWF menetapkan regulasi tentang pemeringkatan tim nasional negara anggotanya dan pemain-pemain bulu tangkisnya.

Peraturan-peraturan yang ada di dalam permainan bulu tangkis diantaranya adalah memiliki panjang lapangan 13,40 meter, lebar lapangan 6,10 meter, jarak garis servis depan dari garis net 1,98 meter, jarak garis servis tengah dari garis samping lapangan 3,05 meter, jarak garis belakang untuk permainan ganda dari garis belakang lapangan 0,76 meter, jarak garis samping permainan tunggal dari garis pinggir lapangan 0,46 meter, tinggi tiang net 1,55 meter, tinggi 1,52 meter. Shuttlecock mempunyai berat 4,8-5,6 gram dan mempunyai 14-16 helai bulu yang diletakan pada kepala gabus yang berdiameter 2,5-2,9 cm. Panjang bulu-bulu dari ujung bawah sampai dengan ujung yang menempel pada dasar gabus kepalanya $6,2-6,9 \mathrm{~cm}$.

\section{Perancangan}

\section{Infografis}

Infografis adalah sebuah representasi visual informasi yang menggunakan visual sebagai isyaratuntuk mengomunikasikan informasi. Tidak perlu berisi jumlah data yang tertentu, memiliki kompleksitas tertentu, atau analisis tertentu. Selain itu, informasi berupa data yang disampaikan cukup komprehensif (menyeluruh) dan mudah dimengerti (Lankow dkk. 2014: 22). Berikut adalah landasan kokoh yang dapat digunakan oleh siapa saja untuk menetapkan nilai visualisasi dan pembagian kategori ini dapat saja menimbulkan pengaruh-pengaruh positif terhadap infografis yaitu (Lankow dkk. 2014: 23-25):

Perancangan infografis dapat diistilahkan dengan berbagai kata, seperti data visualization, information design, dan information architecture. Untuk memikat audiens yang sangat memerlukan informasi, agar penuh penghayatan dan mempertahankan informasinya infografis memanfaatkan cara-cara visual (Lankow dkk., 2014: 12).

Dari beberapa jenis infografis yang ada, maka dalam perancangan ini digunakan jenis infografis dinamis. Infografis dinamis memadukan konsep audio-visual, juga memadukan gambar bergerak dan latar belakang suara yang mampu memperkuat pesan yang ingin disampaikan dapat memberikan keterkaitan yang lebih pada audience, hal ini terlihat pada tampilannya yang dapat disajikan dalam bentuk 2 dimensi maupun 3 dimensi sehingga akan tampak lebih kompleks sehingga dengan infografis ini audience dapat mempelajari dan mengetahui sejarah perkembangan bulu tangkis di Indonesia dengan lebih mudah karena data dari informasi yang disajikan dengan infografis ini akan lebih terasa menyenangkan dibandingkan dengan infografis statis.

\section{Ikon}

Charles Peirce berpendapat bahawa kehidupan manusia adalah pencampuran tanda. Manusia saling bertukar tanda baik verbal maupun non-verbal demi keberlangsungan komunikasi. Selain bertukar tanda, manusia juga melakukan penafsiran terhadap tanda itu sendiri. Tanda merupakan represesntasi konsep, benda, gagasan, dan lai-lain sebagai pengacuan objek (Danesi, 2004: 37). Di antaranya adalah ikon, ikon merupakan tanda bentuk repiklasi, simulasi, imitasi, untuk mewakili acuan. Sebuah tanda dirancang untuk mepresentasikan sumber acuan melalui simulasi atau persamaan (Danesi, 2004: 38-39). Sebuah tanda yang ada secara visual dibuat semirip 
munkin dengan acuannya. Dengan begitu, pemakai sangat mengenali karena kemiripannya itu (Budiman, 2004: 29). Pembentukan ikon mampu memengaruhi manusia dalam penafsiran.

\section{Warna}

Penggunaan warna dalam infografis meliputi: 1) Warna memiliki asosiasi, simbol, dan makna yang dapat dijadikan konsep pertimbangan merancang; 2) Pertimbangan pemilihan warna dapat berubah karena siapa target audiens dan/atau target marketnya, dan/atau identitas apa yang ingin direpresentasikan, dan/atau apa tema yang diangkat, dan/atau apa yang ingin ditampilkan; 3) Warna menimbulkan kemenarikan baik secara fisik maupun psikologis audiens yang melihatnya, memisahkan kategori atau antar bagian dalam konten sehingga mempermudah pemahaman, menyatukan keseluruhan bagian, memberi penekanan pada konten tertentu yang ingin ditonjolkan, menciptakan kontras antara figure (gambar maupun teks) dengan ground (latar belakang) sehingga mudah terlihat oleh audiens, dan memungkinkan untuk diingat pesan di dalamnya sehingga aspek penting, yaitu daya pikat, komprehensi dan retensi dapat terpenuhi (Listya, 2018: 18). Warna yang digunakan adalah warna merah dan biru, warna merah melambangkan semangat atau energi, keberanian. Warna biru melambangkan sejuk, nyaman, tenang

\section{Hasil Perancangan Ikon}

Perancangan ikon yang pertama ada kaitannya dengan negara Inggris, salah satunya jembatan sebagai penggabungan dua design jembatan, yaitu angkat dan gantung yang berdekatan dengan London Tower dan diberi nama Tower Bridge.

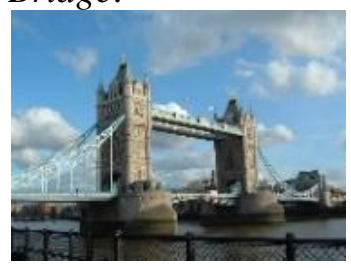

Gambar 1 Referensi

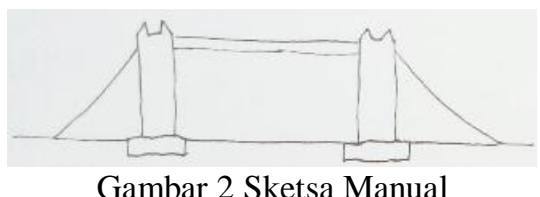

Gambar 2 Sketsa Manual

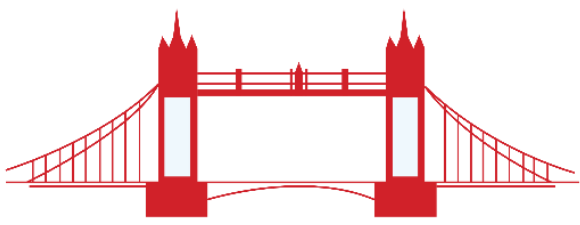

Gambar 3 Computerized Design

Perancangan ikon yang kedua masih berhubungan dengan negara Inggris, yaitu Bus Tingkat yang siap mengantar para wisatawan dari dalam maupun luar negeri untuk berkeliling kota London.

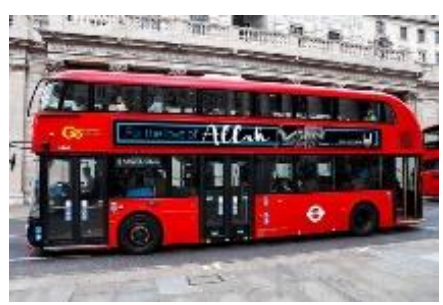

Gambar 4 Referensi 


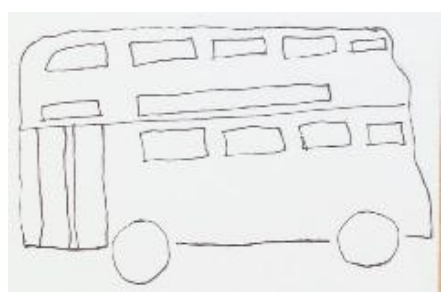

Gambar 5 Sketsa Manual

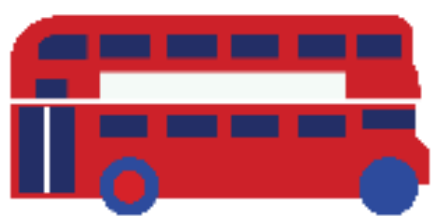

Gambar 6 Computerized Design

Perancangan ikon yang ketiga masih juga berkaitan dengan Inggris, yaitu ikon menara jam atau biasa disebut dengan Big Ben yang secara resmi menara ini diberi nama Elizabeth Tower yang bertepatan dengan pesta 60 tahun ratu Elizabeth memimpin Britania Raya serta wilayah persemakmurannya dan berhasil dibangun pada tahun 1858.

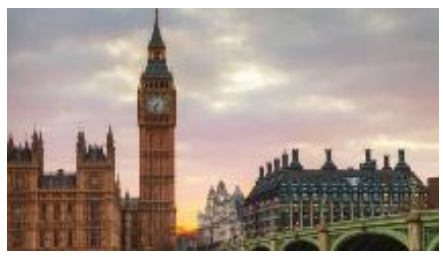

Gambar 7 Referensi

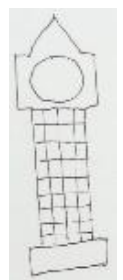

Gambar 8 Sketsa Manual

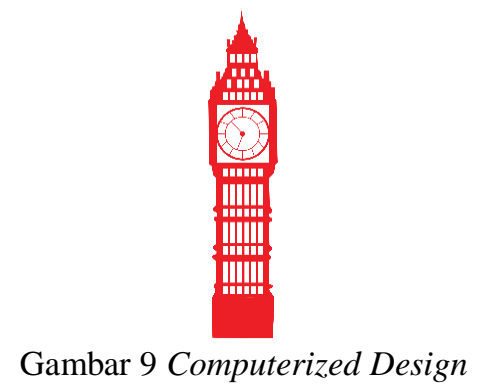

Ikon yang keempat merupakan gambar beberapa benua dan juga negara. Dalam peta ini merupakan sebuah perjalanan awal mulanya bulu tangkis dari Negara Inggris sampai dengan ke Negara Indonesia. 


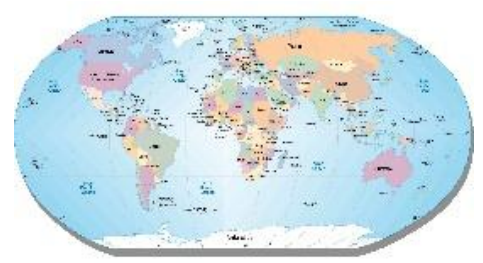

Gambar 10 Referensi

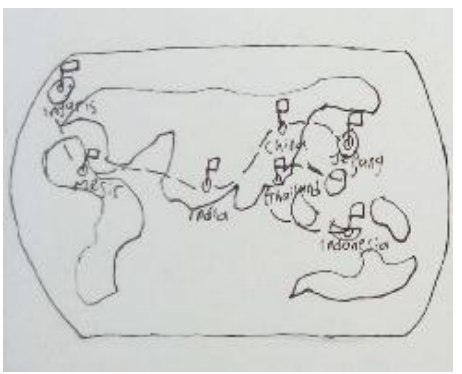

Gambar 11Sketsa Manual

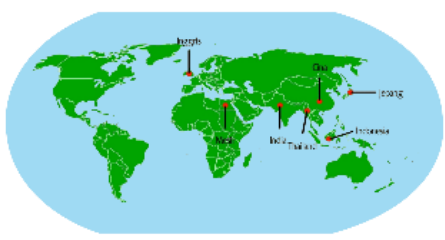

Gambar 12 Computerized Design

Perancangan ikon untuk yang kelima itu adalah terkait bentuk lapangan bulu tangkis. Pada tahun 1877 terbentuknya peraturan bulu tangkis di area lapangan bulu tangkis seperti dengan ukuran lapangannya dan luas pemain ganda dan single yang berbeda-beda.

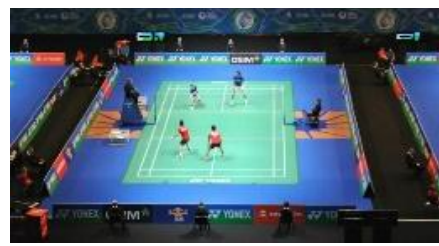

Gambar 13 Referensi

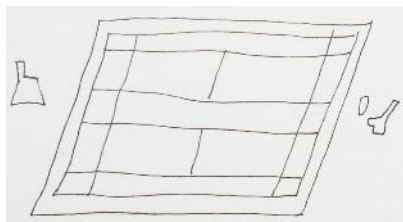

Gambar 14 Sketsa Manual

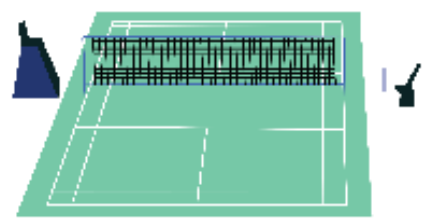

Gambar 15 Computerized Design

Di dalam sebuah lapangan bulu tangkis terdapat jaring atau net yang berfungsi sebagai pemisah antar lawan dan sebagai penentu point. Oleh sebab itu, perancangan yang keenam terkait net. 


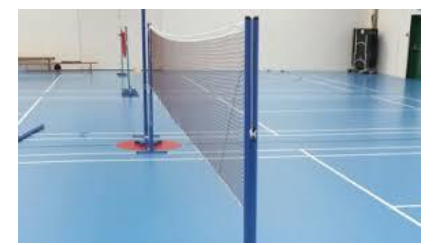

Gambar 16 Referensi
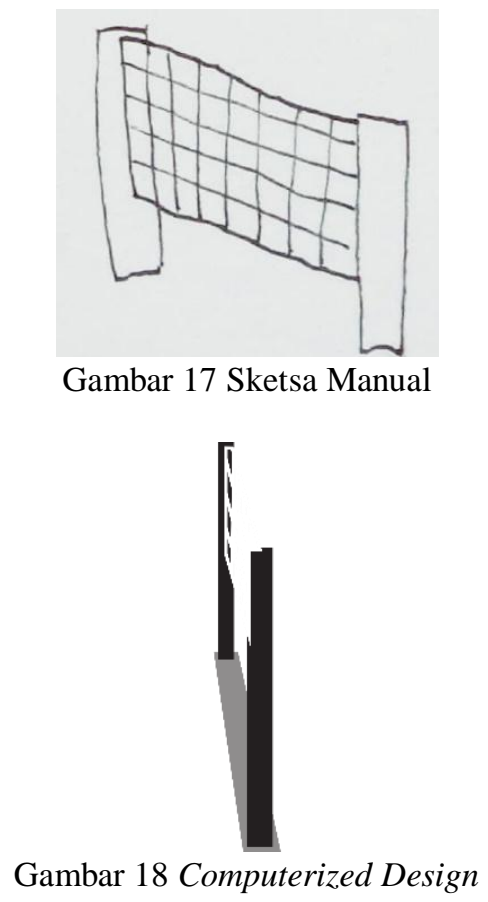

Perancangan ikon yang ketujuh berhubungan dengan alat, yaitu raket. Raket adalah alat untuk memukul Kok atau Shuttlecock yang digunakan saat sedang bermain bulu tangkis untuk mengembalikan bola kepada lawan dan menjaga agar bola tidak jatuh ke tanah.

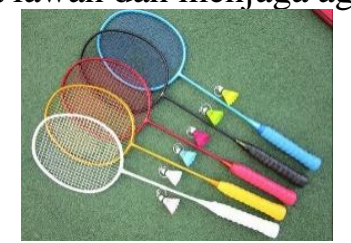

Gambar 19 Foto Referensi

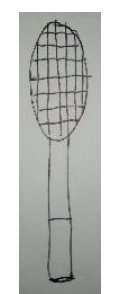

Gambar 20 Sketsa Manual 


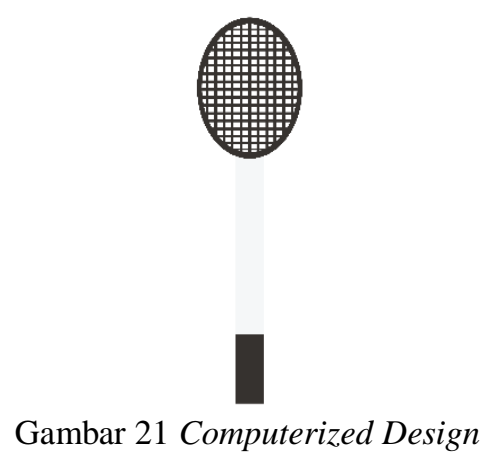

Perancangan ikon yang kedelapan terkait dengan alat lagi, yaitu bola. Bola yang digunakan untuk permainan bulu tangkis adalah kok atau Shuttlecock yang terbuat dari gabus untuk kepalanya agar menjadi beban berat saat memukul dan ditambah dengan bulu-bulu di atasnya.

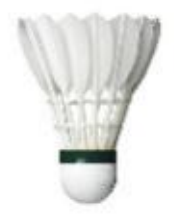

Gambar 22 Referensi

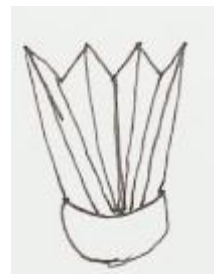

Gambar 23 Sketsa Manual

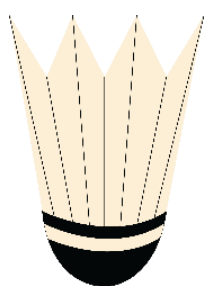

Gambar 24 Computerized Design

Oleh sebab itu, diperlukan perancangan ikon sebagai simbolisasi cikal bakal perbulu tangkisan Indonesia. Pada tahun 1951 merupakan awal sejarah bulu tangkis di Indonesia yang melahirkan PBSI (Persatuan Bulu Tangkis Indonesia) yang diketuai oleh Dick Sudirman atau lebih dikenalnya sebagai bapak bulu tangkis Indonesia.

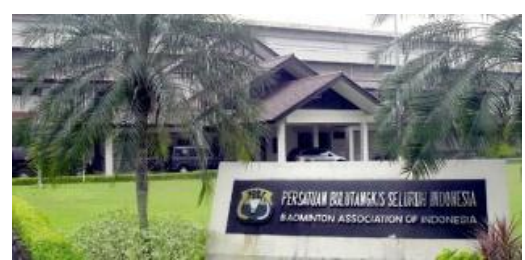

Gambar 25 Referensi 


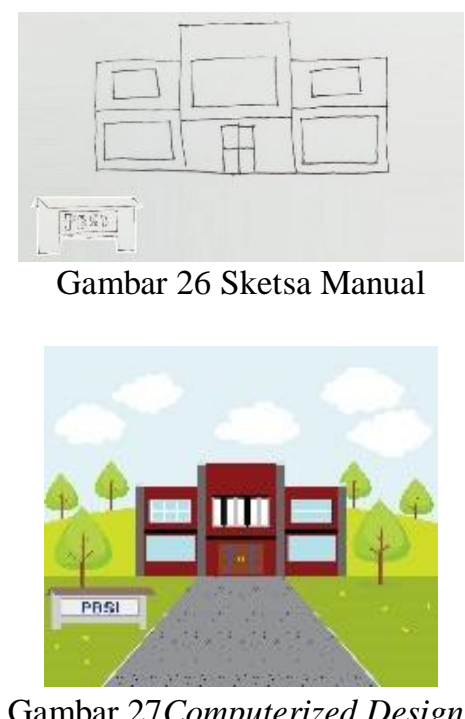

\section{SIMPULAN}

Infografis dinamis merupakan media yang saat ini sedang diminati oleh khalayak karena sifatnya yang audio visual, aksesnya yang mudah, dan atraktif. Konsep dan penggunaan warna dalam perancangan ikon infografis perlu dipertimbangkan dengan baik karena dapat menimbulkan 3 aspek penting infografis, yakni daya tarik, komprehensi, dan retensi. Dengan ini, objek perkembangan bulu tangkis Indonesia dibuat ke dalam suatu media infografis dinamis yang menyerupai sumber aslinya agar banyak masyarakat yang melihat dan juga mengamati termasuk juga untuk anak-anak supaya mereka bisa mengenal perkembangan bulu tangkis Indonesia dari usia dini.

\section{DAFTAR PUSTAKA}

Budiman, K. (2004). Semiotika visual. Yogyakarta: Buku Baik.

Danesi, M. (2004). Pesan tanda dan makna. Yogyakarta: Jalasutra.

Danesi, M. (2004). Pesan, tanda, dan makna: buku teks besar mengenai semiotika dan teori komunikasi. Yogyakarta: Jalasutra.

Ghony, D., \& Almanshur, F. (2014). Metodologi penelitian kualitatif. Yogyakarta: Ar-Ruzz Media.

Lankow, J., Ritchie, J., \& Crooks, R. (2014). Infografis: Kedasyatan cara bercerita visual. Kompas Gramedia.

Listya, A. (2018). Konsep dan penggunaan warna dalam infografis. Jurnal Desain, 6(1), 10-19.

Yuliawan, D. (2017). Bulu tangkis dasar. Yogyakarta: Deepublish. 